\title{
Automatic procedure for analysis and geometry definition of axisymmetric domes by the membrane theory with constant normal stress
}

\section{Processo automático para análise e definição de geometria de cúpulas axissimétricas pela teoria de membrana com tensões normais constantes}
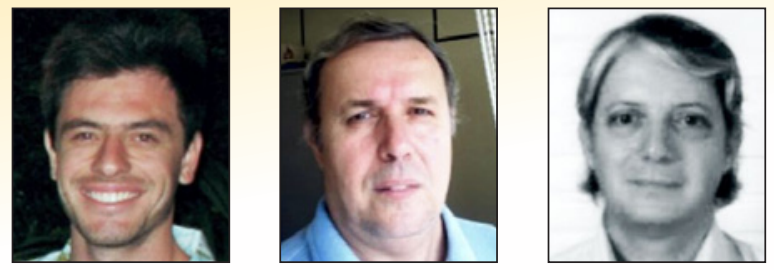

F. T. RABELLO a fernando.rabello@ifsc.edu.br

N. A. MARCELLINO b narbal.marcellino@ecv.ufsc.br

D. D. LORIGGIO daniel.loriggio@ufsc.br

\begin{abstract}
This paper presents an automatic procedure using the membrane theory of shells to analyse and define geometries for axisymmetric domes subjected to its own weight, varying its thickness and bend radius, to obtain constant normal stresses along the structure. The procedure offers a great advantage over the analytic solution of the problem and usual shell numerical methods when one wants to determine the dome geometry with constant stresses, since the presented procedure has the goal stress as input value for obtaining the geometry, as opposed to the usual numerical methods, where the reverse occurs. An example clarifies the differences between a spherical dome with constant thickness and a dome subjected to constant stress. The convergence of the method for a specific material weight and stress for a dome are also presented.
\end{abstract}

Keywords: domes, thin shells, membrane theory, meridional stress, tangential stress.

\section{Resumo}

Este artigo apresenta um processo automático para análise e definição de geometria pela teoria de membrana para cúpulas de revolução axissimétricas submetidas ao peso próprio, com variação de espessura e raios de curvatura, de modo a obter tensões normais tangenciais e meridionais constantes em qualquer ponto da estrutura. O processo apresenta grande vantagem sobre a solução analítica do problema e a por métodos numéricos usuais de casca quando se deseja determinar a geometria da cúpula em função de apenas uma tensão solicitante constante, uma vez que o processo tem como dado de entrada a própria tensão inicial para obtenção da geometria, diferente dos métodos numéricos usuais, onde ocorre o inverso. Um exemplo explicita as diferenças entre uma cúpula esférica com espessura constante e uma cúpula com tensões constantes submetida ao peso próprio. A verificação da convergência do método para uma tensão solicitante e peso específico do material de uma cúpula também são apresentados.

Palavras-chave: cúpulas, cascas finas, teoria de membrana, tensões meridionais, tensões tangenciais. 


\section{Introdução}

Thin shells are curved laminar structures, whose thickness is small when compared to its other dimensions. These elements may be subject to membrane and bending stresses, depending on its restraints and loadings. Axisymmetric loading structures with proper restraint configuration can display only membrane stresses that act in parallel to a plane tangent to the mean surface of the shell at a given point, which can be considered the stresses equalty distributed throughout its thickness.

Shells are a type of structure that has a wide range of applications , including, for example, fuselages of airplanes and submarines, metal silos, sheds covers, building structures, automotive and aerospace components, pressure vessel, liquid tanks, missiles and, among others, domes.

Domes are semi-spherical or similar form shells, which structure may consist of various materials and their varied uses and architectural conceptions refer back to prehistory.

Among the advantages of the use of domes, may be mentioned the possible large spans to be covered, low weight, high stiffness and the possibility of geometric handling in their design, which in many cases make them architecturally beautiful. Constructive difficulties and the high costs may be mentioned often as drawbacks [8].
The construction of the first technically advanced domes began in Europe with the Roman Architectural Revolution, when such structural system was often used to shape large interior spaces of temples and public buildings [12]. The material typically used in these domes construction did not have great tensile strength, so, in order to reduce its weight, the thickness and aggregate material would vary as height increased, and thereby reduce regular stress in the direction of the meridians in the completed structure. One example is the Pantheon in Rome (Figure 1), originally built in $27 \mathrm{BC}$. With 43.4 meters porthole, the Pantheon in Rome remained the world's largest dome for more than a millennium and is currently the largest dome in the world made of non-reinforced concrete.

The geometry of the domes directly influences its structural performance. Therefore, for a given material having certain characteristics, structural efficiency is directly related to the efficiency of its shape, including its thickness and radii of curvature. There is a trend of research in the pursuit of optimization of the geometry of this type of structure, as can be seen in [1], [2], [3], [4] e [7]. One of the main factors for this interest are the advances and accessibility of computers and the development of numerical models and optimization algorithms for solving such problems [1]. Solutions for numerical methods with optimization algorithms are suitable for more general cases of geometries and loads, while there is still a conflict between the computational cost, the accuracy of the results

\section{Figure 1 - Section of the Rome Pantheon dome (6)}

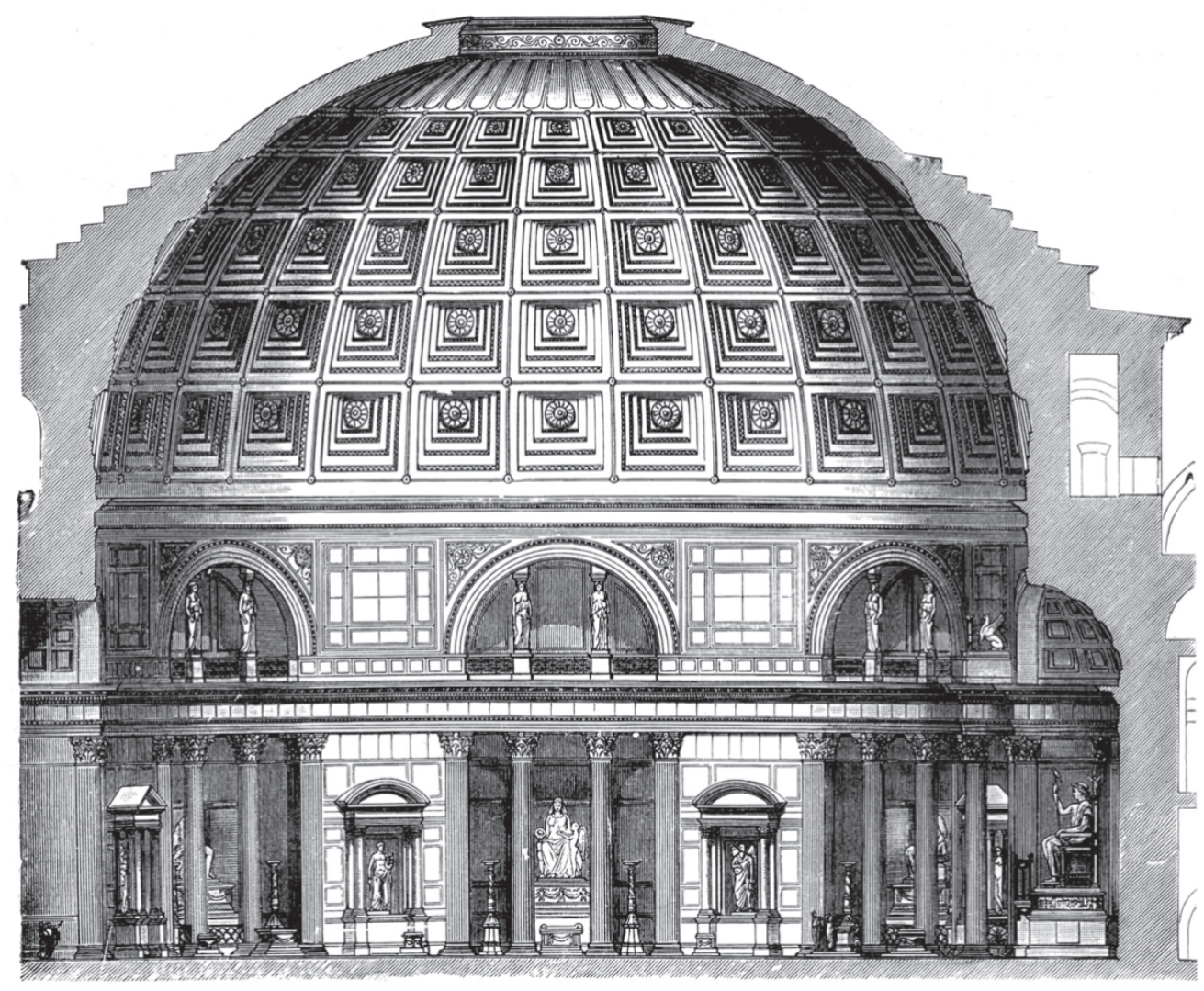


obtained and the mathematical complexity of the solutions [3]. The approach can also present some convergence problems, which some analyzes have values of stresses or displacements that are not even found in the field of real numbers [3].

This paper proposes an automatic process for the analysis and definition of thin shells segments revolution geometry (domes) submitted to its own weight by membrane theory with thickness and radii of curvature variation in order to obtain meridional and tangential stresses constant by a process of simple implementation and low computational cost. The process has advantage over the usual numerical methods bark, such as the finite element method, when it is desired to determine the geometry of the dome due to a constant stress, since the process has its own initial tension as input to obtaining geometry, different from the usual numerical methods, where the reverse occurs. Furthermore, the exact analytic solution of the problem is extremely difficult, as shown in methodology, which makes the presented process quite interesting for solving such structures. A dome with constant meridional and tangential stresses tends to provide a design with a good use of the material across the dome and decrease bending moments and shear stresses that may be significant for other types of geometry. According to the membrane theory, the stiffness to flexure and torsion in the shell should not be considered, which causes the bending and torsional moments to resulting null. Under these conditions, also only normal and tangential forces will request cancel each other out the shear forces and the shell. For this theory to be valid, it must meet the following conditions:

- The law of variation of the mean surface curvature is continuous;

- The law of variation of the thickness of the shell is continuous;

- The distribution of loads applied on the surface is continuous;

- The forces applied to the free edges act in the corresponding planes tangent to the mean surface;

- Support reactions are contained in tangent planes to the mean surface.

Lamé, French engineer whose solution is sometimes also called the Lamé problem, originally settled the general solution of the axi- symmetric revolution cylinder thick walls problem in 1833 . The initial solution was based on a cylinder subjected to internal pressure, which is made use of linear relationships of Hooke's Law. The formulation presented in this paper considers only the equilibrium equations of the domes. Thus, no material property is used and its use is not restricted to elastic materials. However, these equations are valid for situations where the thickness of the dome does not exceed $10 \%$ of the internal radius, remaining the error rate small [15]. Using Lamé equations and the ones presented in this work, it can be seen by Figure 2, the variation in tangential stress $\sigma_{\theta}$ of revolution walls shells subjected to internal pressure $\pi$, when there are revolution shells with a thickness equal to $10 \%$ of the inner radius and the thickness of the cylinder is equal to $400 \%$ of the inner radius.

\subsection{Objective}

The objective of this paper is to present a process using the membrane theory for analyzing and defining the geometry of an axisymmetric dome subjected to its own weight, with varying thickness and curvature radii, in order to obtain constant normal and shear stresses.

\section{Method}

\subsection{Equilibrium equations}

In the case of domes studied in this work, it is presented the equilibrium equations of the membrane theory for thin shells subjected to loads with revolution symmetry. For such structures, due to its symmetry, the following characteristics are presented:

$N_{\theta}=N_{\theta}(\theta)$;

$N_{\varphi \theta}=N_{\theta \varphi}=0$;

$p_{\varphi}=p_{\varphi}(\varphi)$;

$p_{\theta}=0$

\section{Figure 2 - Variation of the tangential stresses on the wall of the revolution shells, due to internal pressure in function of their thickness (11)}
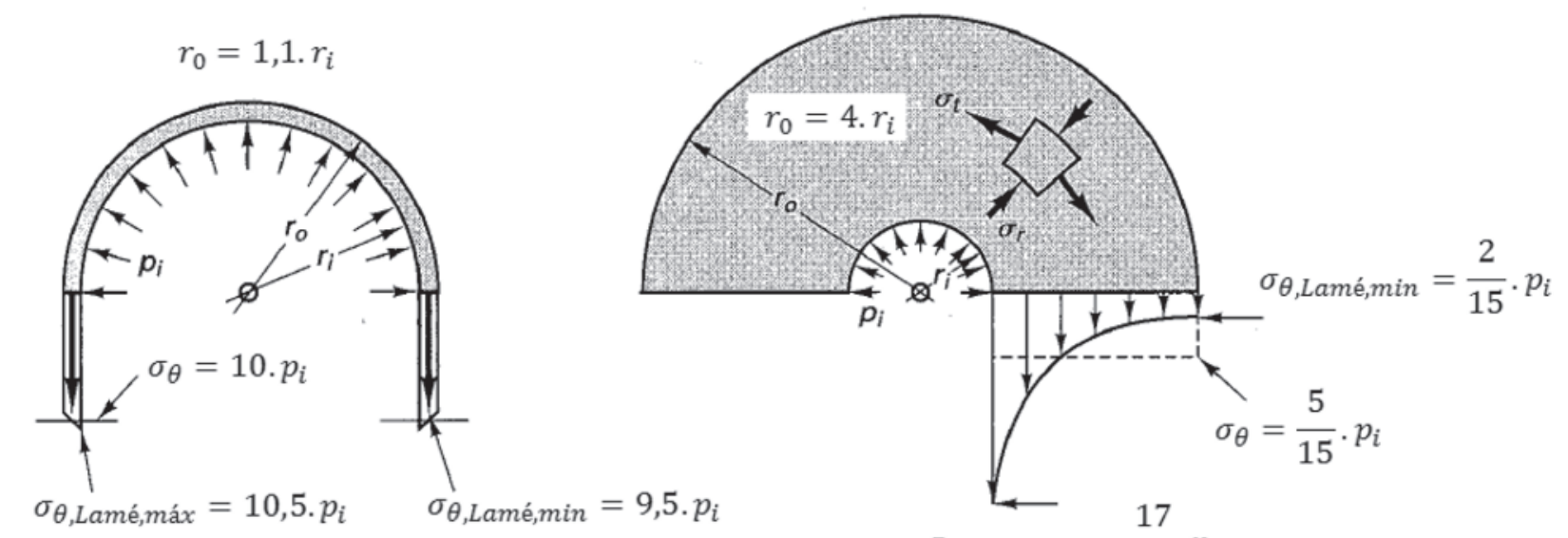

$\sigma_{\theta, \text { Lamé,máx }}=\frac{17}{15} \cdot p_{i}$ 


\section{Figure 3 - Dome and infinitesimal surface element}
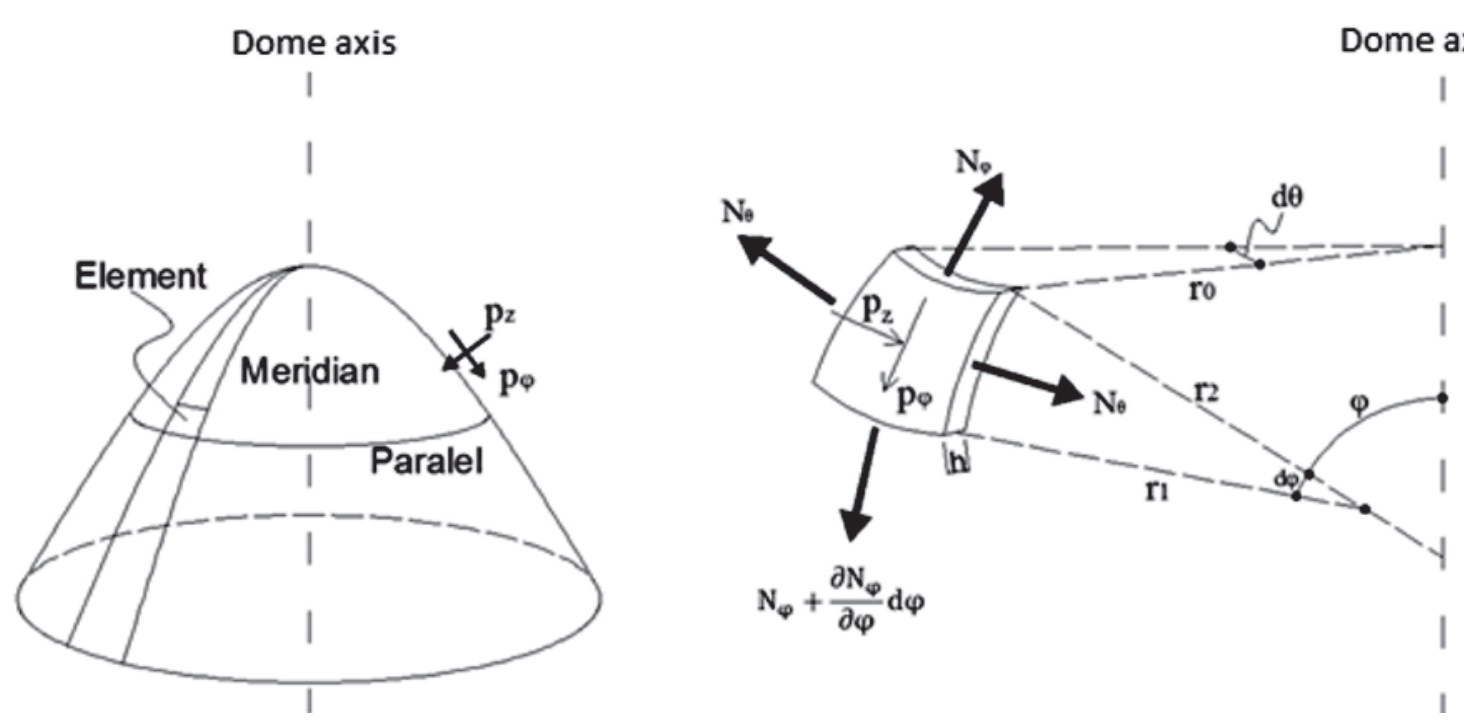

$p_{z}=p_{z}(\varphi)$

where:

$N_{\varphi}-$ Normal force per unit of length in the direction of the meridian;

$N_{\theta}$ - Normal force per unit of length in the direction parallel;

$N_{\varphi \theta}, N_{\theta \varphi}$ - shear forces per unit of length;

$p_{\varphi}$ - Loading tangent to the surface of the shell in the direction of the meridian;

$p_{\theta}$ - Loading tangent to the surface of the shell in the direction parallel;

$p_{z}$ - Loading perpendicular to the surface of the shell.

It's possible to completely define the geometry of a dome by its thickness $h$ and the radii of curvature $r_{1}$ and $r_{2}$ arbitrarily variable (Figure 3 ). The radius $r_{2}$ has its center of curvature located on the axis of the shell and it generates the surface of the shell in the perpendicular direction to the tangent to the meridian. On the geometry of the shells, one can also define the radius $r_{0}$, which lies in a plane perpendicular to the axis of the shell and has a proportion to $r_{2}$ equal to $r_{0}=r_{2} \cdot \operatorname{sen} \varphi$. It is assumed that the thickness $h$ is very small compared to $r_{1}$ and $r_{2}$ and therefore no distinction is made between the inner, middle and outer radii of the dome.

Due to the symmetry of the dome there is an axisymmetric load condition. This leads the structure to have tangential constant forces $N_{\theta}$ on each side of the infinitesimal element of the dome surface, which does not occur with the meridional force $N_{\varphi}$. The shear forces $N_{\varphi \theta}$ and $N_{\theta \varphi}$ are canceled due to the symmetry of the problem.

The infinitesimal element of the surface of the dome on Figure 2 is subjected to external forces in the direction of the meridian $\left(p_{\varphi}\right)$ and in the normal direction to the surface ( $p_{z}$ is positive entering the dome).

Using the equation:

$$
\mathrm{r}_{0}=\mathrm{r}_{2} \cdot \operatorname{sen} \varphi
$$

On the upper side of the element:

$$
\mathrm{N}_{\varphi} \mathrm{r}_{0} \mathrm{~d} \varphi=\mathrm{N}_{\varphi} \mathrm{r}_{2} \cdot \operatorname{sen} \varphi \mathrm{d} \varphi
$$

and on the inferior side

$$
\left(\mathrm{N}_{\varphi}+\frac{\partial \mathrm{N}_{\varphi}}{\partial \varphi} \mathrm{d} \varphi\right)\left(\mathrm{r}_{0}+\frac{\mathrm{dr}_{0}}{\mathrm{~d} \varphi} \mathrm{d} \varphi\right) \mathrm{d} \theta
$$

As these forces are not collinear (Figure 4), a component appears in the direction $z$ equal to:

$$
\mathrm{N}_{\varphi} \mathrm{r}_{0} \mathrm{~d} \theta \mathrm{d} \varphi
$$




\section{Figure 4 - Normal component of the meridional force $\mathrm{N}_{\varphi}$}

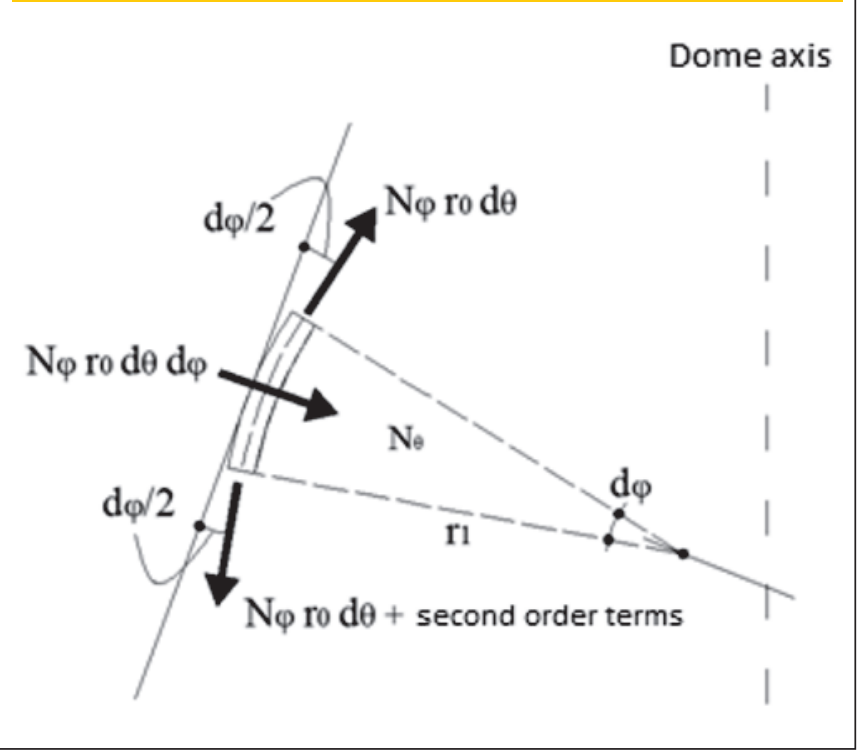

In the parallel direction, the forces on the element right and left are also not collinear (Figure 5), therefore a component force appears.

$$
\mathrm{N}_{\theta} \mathrm{r}_{1} \mathrm{~d} \varphi \mathrm{d} \theta
$$

This force is horizontally projected in the mean plan of the dome. Projecting this force in the direction tangent to the meridians:

$$
\mathrm{N}_{\theta} \mathrm{r}_{1} \mathrm{~d} \varphi \mathrm{d} \theta \cos \varphi
$$

And in the normal direction to the mean surface:

$$
\mathrm{N}_{\theta} \mathrm{r}_{1} \mathrm{~d} \varphi \mathrm{d} \theta \operatorname{sen} \varphi
$$

Taking the sum of the forces in the tangent direction to the meridian in equations (2), ( 3 ) and (6) equal to zero, neglecting second order terms and dividing the equation by $d \varphi d \theta$, equation (8) is shown:

$$
\frac{\mathrm{d}\left(\mathrm{N}_{\varphi} \mathrm{r}_{0}\right)}{\mathrm{d} \varphi}-\mathrm{N}_{\theta} \mathrm{r}_{1} \cos \varphi+\mathrm{p}_{\varphi} \mathrm{r}_{0} \mathrm{r}_{1}=0
$$

Taking the sum of forces in the normal direction to the surface in

\section{Figure 5 - Normal component of the tangential force $\mathrm{N}_{\theta}$}

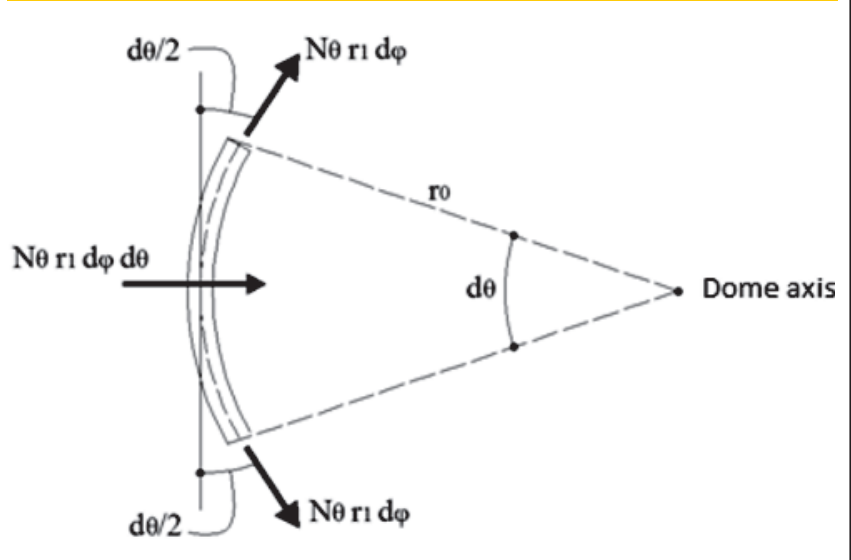

equations (4) and (7) equal to zero and dividing the equation by $d \varphi d \theta$ and $r_{1} r_{2} \operatorname{sen} \varphi$ :

$$
\frac{\mathrm{N}_{\varphi}}{\mathrm{r}_{1}}+\frac{\mathrm{N}_{\theta}}{\mathrm{r}_{2}}=-\mathrm{p}_{\mathrm{z}}
$$

One can determine the unknown forces on the membrane by means of free-body analysis of whole shell, over a parallel circle. From equation (9) writes the equation (10):

$$
\mathrm{N}_{\theta}=-\mathrm{p}_{\mathrm{z}} \mathrm{r}_{2}-\frac{\mathrm{N}_{\varphi}}{\mathrm{r}_{1}} \mathrm{r}_{2}
$$

\section{Figure 6 - Equilibrium diagram of a shell segment}

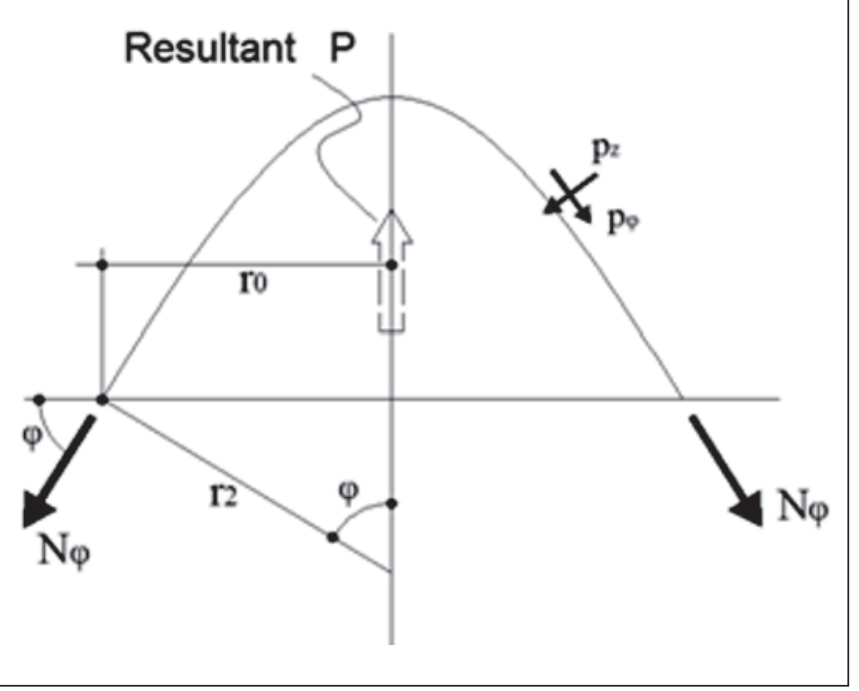




\section{Figura 7 - Diagrama de equilíbrio da força de compressão em um contorno}

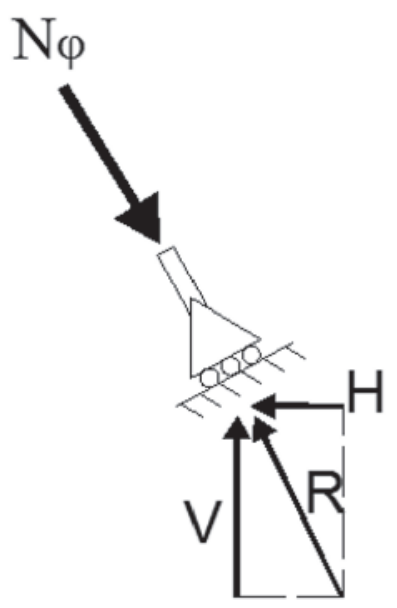

Moreover, substituting (10) into (8), one has:

$$
\frac{d\left(N_{\varphi} r_{0}\right)}{d \varphi}-\left(-p_{z} r_{2}-\frac{N_{\varphi}}{r_{1}} r_{2}\right) r_{1} \cos \varphi=-p_{\varphi} r_{0} r_{1}
$$

Substituting (1) into (11) and multiplying by $\operatorname{sen} \varphi$ :

$$
\begin{aligned}
& \frac{d\left(N_{\varphi} r_{0}\right)}{d \varphi} \operatorname{sen} \varphi+N_{\varphi} r_{0} \cos \varphi= \\
& -p_{z} r_{1} r_{2} \operatorname{sen} \varphi \cos \varphi-p_{\varphi} r_{1} r_{2} \operatorname{sen}^{2} \varphi
\end{aligned}
$$

\section{where}

Therefore:

$$
\frac{d}{d \varphi}\left[\left(N_{\varphi} r_{0}\right) \operatorname{sen} \varphi\right]=-r_{1} r_{2} \operatorname{sen} \varphi\left(p_{z} \cos \varphi+p_{\varphi} \operatorname{sen} \varphi\right)
$$

Integrating both sides of equation (13):

$$
\mathrm{N}_{\varphi} \mathrm{r}_{0} \operatorname{sen} \varphi-\mathrm{F}(\varphi)-\mathrm{C}=0
$$

where:

$$
F(\varphi)=\int-r_{1} r_{2} \operatorname{sen} \varphi\left(p_{z} \cos \varphi+p_{\varphi} \operatorname{sen} \varphi\right) d \varphi
$$

In the case of domes without an opening at the top, the constant $C$ is zero. So, multiplying (14) by $2 \pi$ :

$$
2 \pi r_{0} N_{\varphi} \operatorname{sen} \varphi-2 \pi F(\varphi)=0
$$

The vertical resultant force $R$ due to loadings $p_{z}$ and $p_{\varphi}$ is kept in balance by the vertical component of the $N_{\varphi}$ force. The resultant force $P$ (Figure 6 ) for domes without openings on top is given by:

$$
P=2 \pi \int_{0}^{\varphi} r_{1} r_{2} \operatorname{sen} \varphi\left(p_{z} \cos \varphi+p_{\varphi} \operatorname{sen} \varphi\right) d \varphi
$$

By substituting (16) into (15) and isolating $N_{\varphi}$ :

$$
\mathrm{N}_{\varphi}=\frac{\mathrm{P}}{2 \pi \mathrm{r}_{0}(\varphi) \operatorname{sen} \varphi}
$$

One can thus determine the membrane forces in axisymmetric shells of revolution. The support conditions of the domes should always be tangential to $N_{\varphi}$, as shown in Figure 7 .

From Figure 7 it can be seen that only a vertical component $V$ does not satisfy the equilibrium condition. It's possible to cancel the horizontal component $H$. with the addition of a resilient ring for example. However, the adoption of such device causes significant local flexure stresses, which will not be addressed in this paper.

\subsection{Spherical dome}

For the analysis of a spherical dome subjected to own weight is considered constant thickness $\mathrm{h}$ and the radius of curvature $r_{1}=r_{2}$. Consider, therefore, a radius of spherical dome $r_{1}=r_{2}=a$ and constant thickness $h$ subjected to own weight, with $\varphi$ ranging from $0^{\circ}$ to $90^{\circ}$. The resultant $P$ is given by $p$ (own weight force per unit of area) multiplied by $A$ (infinitesimal section area), where $A$ is given by:

$$
\begin{aligned}
& A=\int d A \quad \Rightarrow \quad d A=2 \pi r_{0} d s \\
& A=\int_{0}^{\varphi} 2 \pi a \operatorname{sen} \varphi a d \varphi \Rightarrow A=2 \pi a^{2} \int_{0}^{\varphi} \operatorname{sen} \varphi d \varphi
\end{aligned}
$$

The resultant being $P=p . A$, one can obtain the expression (18):

$$
\mathrm{P}=\mathrm{p} 2 \pi \mathrm{a}^{2} \int_{0}^{\varphi} \operatorname{sen} \varphi \mathrm{d} \varphi \quad \Rightarrow \mathrm{P}=-2 \pi \mathrm{pa}^{2}(1-\cos \varphi)
$$

By substituting equations (18) and (1) in (17), meridional force is:

$$
N_{\varphi}=\frac{-2 \pi p a^{2}(1-\cos \varphi)}{2 \pi a \operatorname{sen}^{2} \varphi}
$$


Figure 8 - Tangential forces $\mathbf{N}_{\theta}$ and meridional forces $\mathbf{N}_{\varphi}$ in function of $\varphi$ on the spherical dome

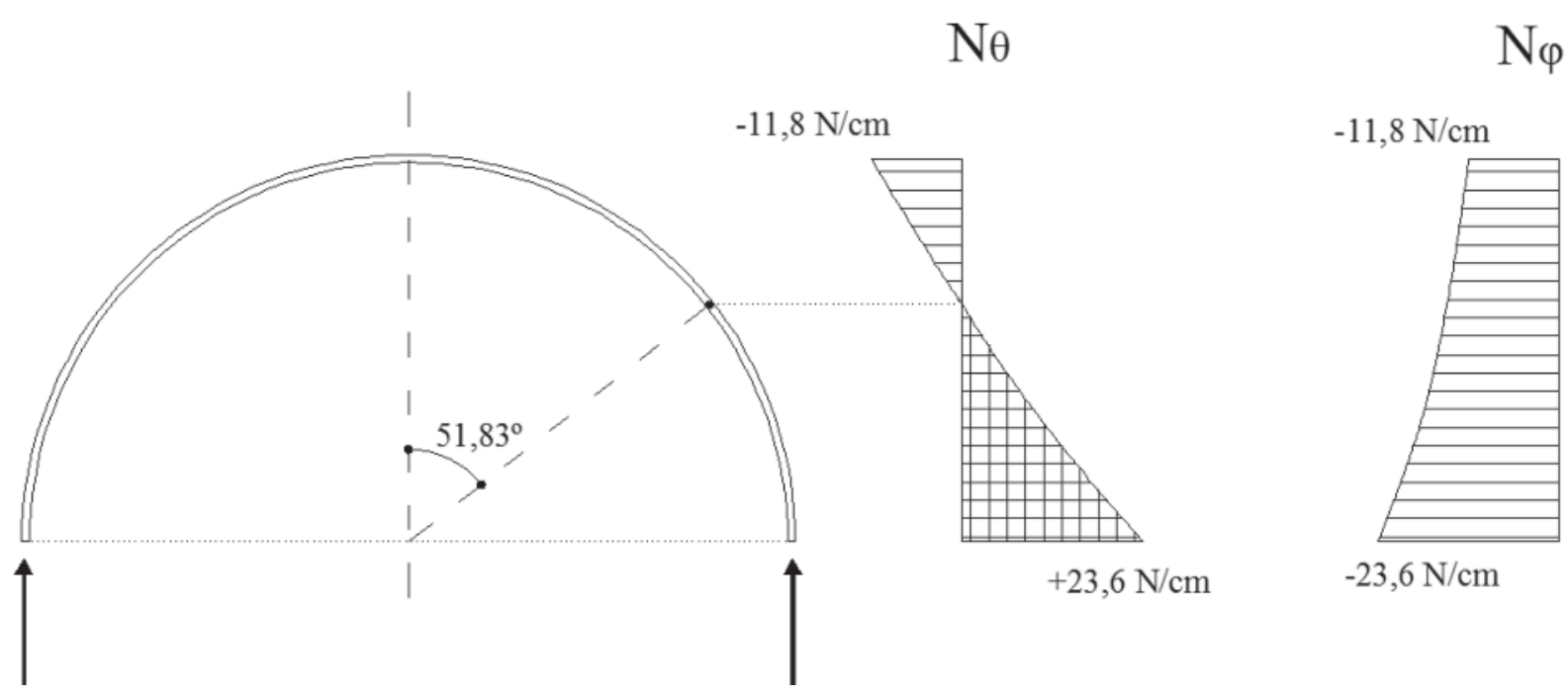

$\therefore N_{\varphi}=-\frac{a p}{(1+\cos \varphi)}$ ou $\sigma_{\varphi}=-\frac{a p}{h(1+\cos \varphi)}$

By solving the equations above, one can obtain the tangential forces of the spherical dome:

In (9) is given:

$N_{\theta}=-p_{z} a-N_{\varphi}$

$\therefore N_{\theta}=-p \cos \varphi a+\frac{a p}{(1+\cos \varphi)}$

$N_{\theta}=a p\left(\frac{1}{(1+\cos \varphi)}-\cos \varphi\right)$ ou $\sigma_{\theta}=\frac{a p}{h}\left(\frac{1}{(1+\cos \varphi)}-\cos \varphi\right)$

Assuming a thickness , e $p=0,0236 \mathrm{~N} / \mathrm{cm}^{2}$, it's possible to draw of meridional and tangential forces diagrams in function of $\varphi$. The results are shown in Figure 8.

Figure 9 - Tangential stresses $\sigma_{\theta}$ and meridional stresses $\sigma_{\varphi}$, respectively $\left(\mathrm{N} / \mathrm{cm}^{2}\right.$ )
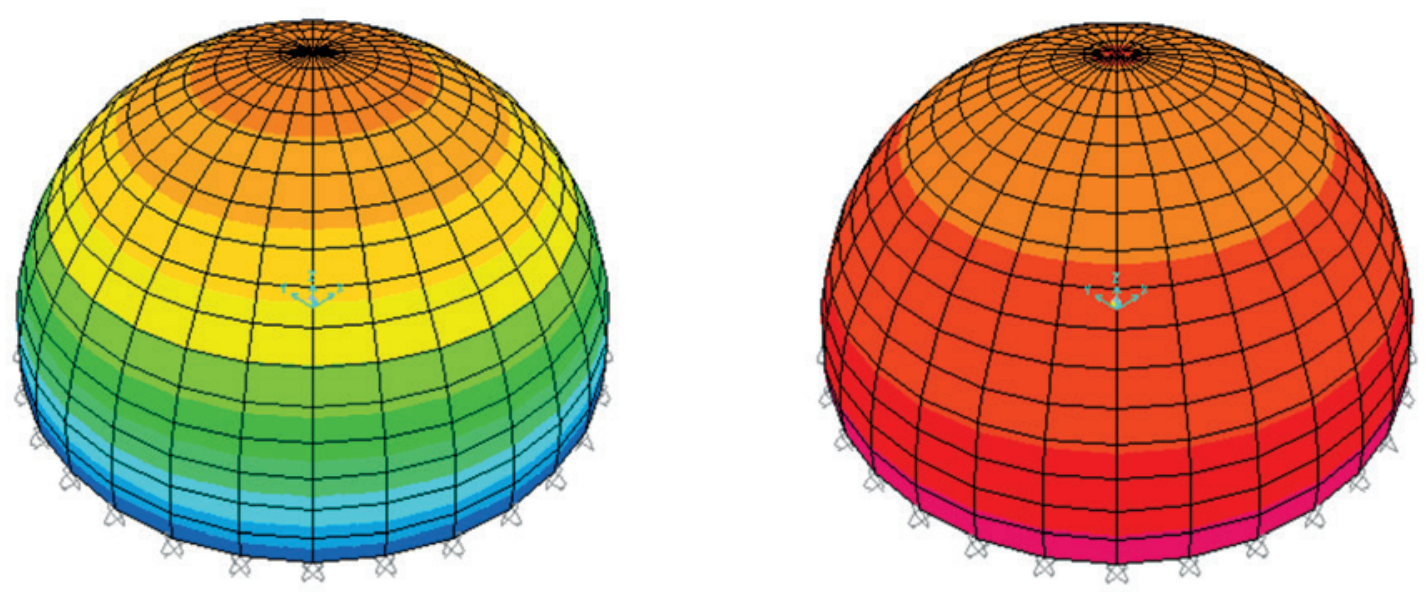

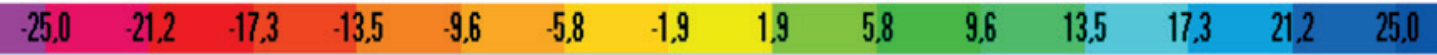




\section{Figure 10 - Shell segment}

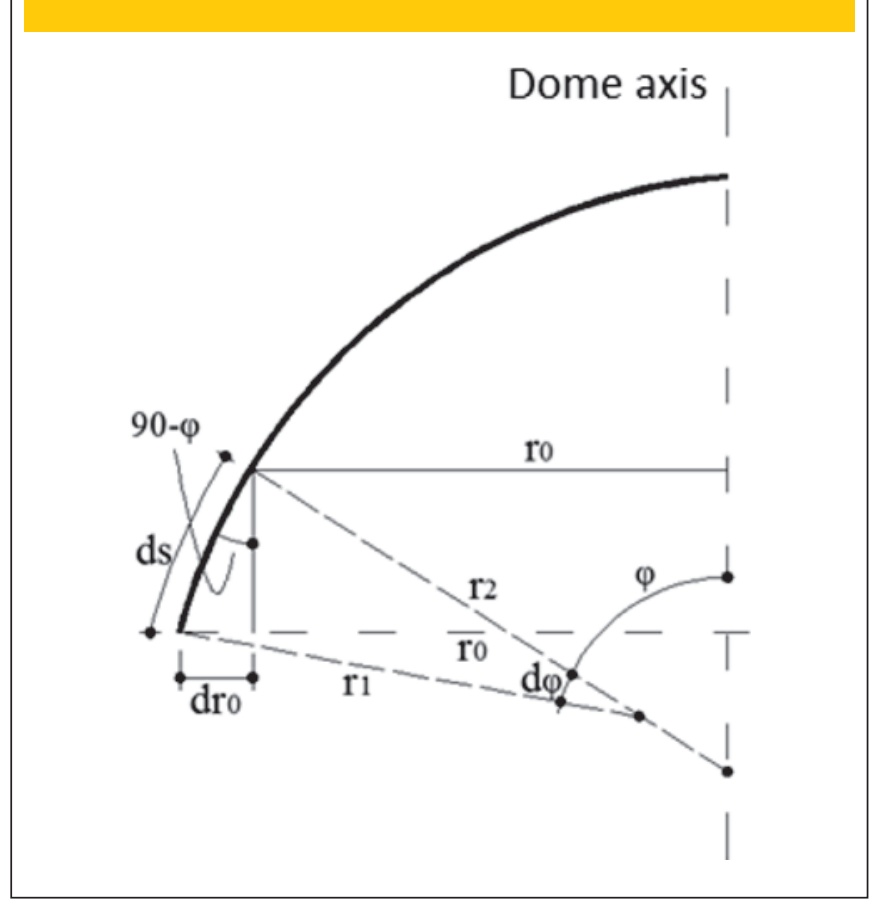

It is noticeable that from $\varphi=0$ to $\varphi=51.827^{\circ}$, no traction force develops at the dome, only compressive forces.

Solving the problem using the finite element method, we obtain a maximum compression force equal to $11,983 \mathrm{~N} / \mathrm{cm}^{2}$ and traction equal to $26,243 \mathrm{~N} / \mathrm{cm}^{2}$. The $\varphi$ angle at which no shear stress develops in the direction parallel dome is approximately $52^{\circ}$. The stress diagram is shown in Figure 9.

\subsection{Constant stresses dome}

On the constant stress dome analysis, it is considered a dome with variable thickness subjected to own weight $p$.

On such domes, should not only their thick- ness vary along the height but also their radii of curvature, so that the meridional and tangential stresses are equal and constant.

The weight per unit of area in the central plane of these summits is given by:

$\mathrm{p}=\gamma \mathrm{h}$

Therefore, $p_{z}$ and $p_{\varphi}$ components are given by:

$$
\mathrm{p}_{\mathrm{z}}=\gamma \mathrm{h} \cos \varphi \quad \mathrm{p}_{\varphi}=\gamma \mathrm{h} \operatorname{sen} \varphi
$$

In the case of domes with constant stresses, the geometry of the meridian is determined in such way that the meridional compressive stresses are constant and equal to $\sigma$ in all directions in its mean plane, with:

$N_{\varphi}=N_{\theta}=-\sigma h$

By replacing in (9):

$$
\sigma h \cdot\left(\frac{1}{r_{1}}+\frac{1}{r_{2}}\right)=\gamma h \cos \varphi
$$

By replacing (1) and isolating .

$$
r_{1}=\frac{r_{0}}{\frac{\gamma}{\sigma} r_{0} \cos \varphi-\operatorname{sen} \varphi}
$$

From Figure 10 is possible to deduce the following relationship:

$$
\mathrm{ds}=\mathrm{r}_{1} \mathrm{~d} \varphi \quad \mathrm{r}_{1} \mathrm{~d} \varphi=\frac{\mathrm{dr}_{0}}{\cos \varphi}
$$

Replacing (23) in (22):

$$
\frac{\mathrm{dr}_{0}}{\mathrm{~d} \varphi}=\frac{\mathrm{r}_{0} \cos \varphi}{\frac{\gamma}{\sigma} \mathrm{r}_{0} \cos \varphi-\operatorname{sen} \varphi}
$$

Integrating both sides of equation (24):

$r_{0}=\int_{0}^{\varphi} \frac{r_{0} \cos \varphi}{\frac{\gamma}{\sigma} r_{0} \cos \varphi-\operatorname{sen} \varphi} d \varphi$

It's obtained:

$$
\begin{aligned}
& r_{0}=-r_{0} \frac{\sigma^{2}}{\left(\sigma^{2}+\gamma^{2} \cdot r_{0}^{2}\right)} \cdot \ln \left[\gamma \cdot r_{0} \cdot \tan \left(\frac{\varphi}{2}\right)^{2}-\right. \\
& \left.\gamma \cdot r_{0}+2 \cdot \tan \left(\frac{\varphi}{2}\right) \cdot \sigma\right]+r_{0} \frac{\sigma^{2}}{\left(\sigma^{2}+\gamma^{2} \cdot r_{0}^{2}\right)} \cdot \\
& \ln \left[1+\tan \left(\frac{\varphi}{2}\right)^{2}\right]+2 \frac{\sigma^{2}}{\left(\sigma^{2}+\gamma^{2} \cdot r_{0}^{2}\right)} \cdot \gamma \cdot r_{0}^{2} \cdot\left(\frac{\varphi}{2}\right)
\end{aligned}
$$

On top of the dome, where $\varphi=0$, the right side of equation (24) becomes undefined. To solve this problem is necessary to use equations (21) and (23). As on the top of the dome $r_{1}=r_{2}$, it follows that :

$r_{1}=r_{2}=\frac{2 \sigma}{\gamma} \quad d r_{0}=r_{1} d \varphi=\frac{2 \sigma}{\gamma} d \varphi$

Therefore, on the top of the dome: 


$$
\frac{\mathrm{dr}_{0}}{\mathrm{~d} \varphi}=\frac{2 \sigma}{\gamma}
$$

Then, the shape of the meridian of the dome with constant stresses can be defined by equations (24) and (26). The variation of the thickness of the dome can be determined by the equations (8) and (20) , which are obtained by dividing the equation for:

$$
-\frac{\mathrm{d}}{\mathrm{d} \varphi}\left(h \mathrm{~h}_{0}\right)+h \mathrm{~h}_{1} \cos \varphi+\frac{\gamma}{\sigma} \mathrm{hr}_{1} \mathrm{r}_{0} \operatorname{sen} \varphi=0
$$

For $\varphi=0$, we obtain the equation (27):

$\frac{d}{d \varphi}\left(h r_{0}\right) \mathrm{n} h r_{1}=h \frac{d r_{0}}{d \varphi}$

Replacing (22) into (27) it follows that:

$$
\frac{\mathrm{d}}{\mathrm{d} \varphi}\left(\mathrm{hr}_{0}\right)=\mathrm{hr}_{0} \frac{\cos \varphi+\frac{\gamma}{\sigma} \mathrm{r}_{0} \operatorname{sen} \varphi}{\frac{\gamma}{\sigma} \mathrm{r}_{0} \cos \varphi-\operatorname{sen} \varphi}
$$

By integrating both sides from 0 a $\varphi$ :

$$
\begin{aligned}
& \text { h. } r_{0}=h \cdot r_{0} \cdot \ln \left[1+\tan \left(\frac{\varphi}{2}\right)^{2}\right]-h \cdot r_{0} \cdot \ln \left[\gamma \cdot r_{0} \cdot \tan \left(\frac{\varphi}{2}\right)^{2}\right. \\
& \left.-\gamma \cdot r_{0}+2 \cdot \tan \left(\frac{\varphi}{2}\right) \cdot \sigma\right]
\end{aligned}
$$

Figure 11 - Graphic determination of the geometry of the dome with Constant stress (5)

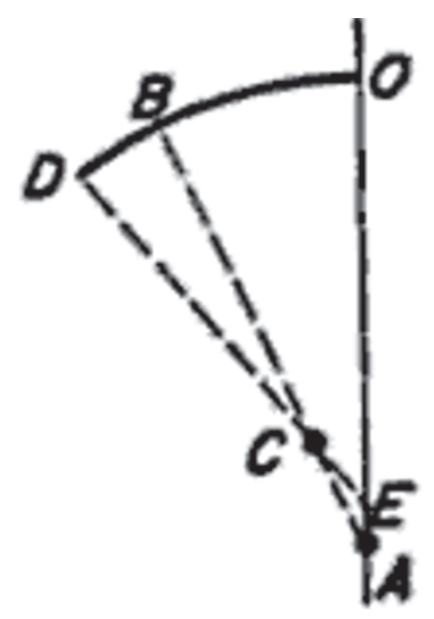

Figure 12 - Geometry of the meridian of the dome

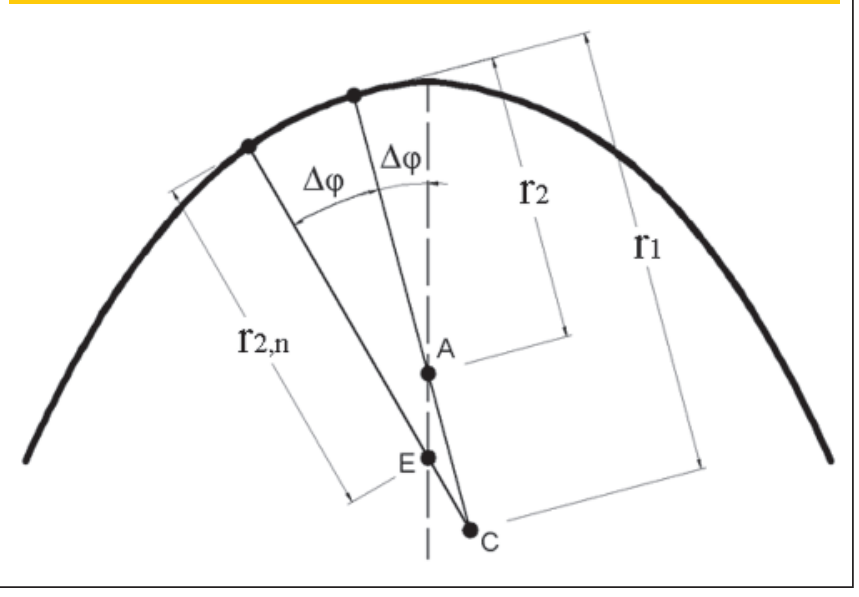

It's possible to then determine the thickness of the dome with constant stresses by equations (27) and (28).

The equations (25) and (29) were obtained by MathCAD computer software. However, because of those functions, whose integrals are not easy to get an analytical solution, it's possible to use numerical integration for its determination, in order to calculate the approximate value of definite integrals using, for example, the trapezoidal rule and Simpson's Rule [10]. One can get the radius of curvature $r_{1}$ and $r_{2}$ by simpler iterative process, presented by [5].

Equation (26) determines the radius at the top of the dome, as it follows:

$r_{\text {topo }}=r_{1}=r_{2}=\frac{2 \sigma}{\gamma}$

Rearranging (21):

$$
\begin{aligned}
& \text { h. } r_{0}=h \cdot r_{0} \cdot \ln \left[1+\tan \left(\frac{\varphi}{2}\right)^{2}\right]-h \cdot r_{0} \cdot \ln \left[\gamma \cdot r_{0} \cdot \tan \left(\frac{\varphi}{2}\right)^{2}\right. \\
& \left.-\gamma \cdot r_{0}+2 \cdot \tan \left(\frac{\varphi}{2}\right) \cdot \sigma\right]
\end{aligned}
$$

Knowing the radius of curvature at the top, one can start the determination of the dome geometry with constant stress, as shown in Figure 11.

A gradual graphic built can be made using equation (30) starting from the top radius $r_{\text {topo }}$, then following the points $A, B, C$, etc. Initially ,the arc from the point $O$ to point $B$ is drawn. At point $B$ the new weight $p_{z}$ is calculated by equation (30), and being $r_{2}=A B$ , one can determine a new curvature radius $r_{1}$ that results greater than the previous radius of curvature $r_{1}$. The extension of the new $r_{1}$ within $r_{2}$ has a new center $\mathrm{C}$, which have a new curvature, larger than the previous one. The iteration of the geometry must be made with approximately equal $\Delta \varphi$. The lower the $\Delta \varphi$, the closer will the values obtained in relation to the exact solution be.

It can be seen from equation (30) the shape of the meridian is determined solely by the stress that is desired as set constant and the specific weight of the material used. Figure 12 shows 


\section{Figure 13 - Triangle ACE for the process automation}

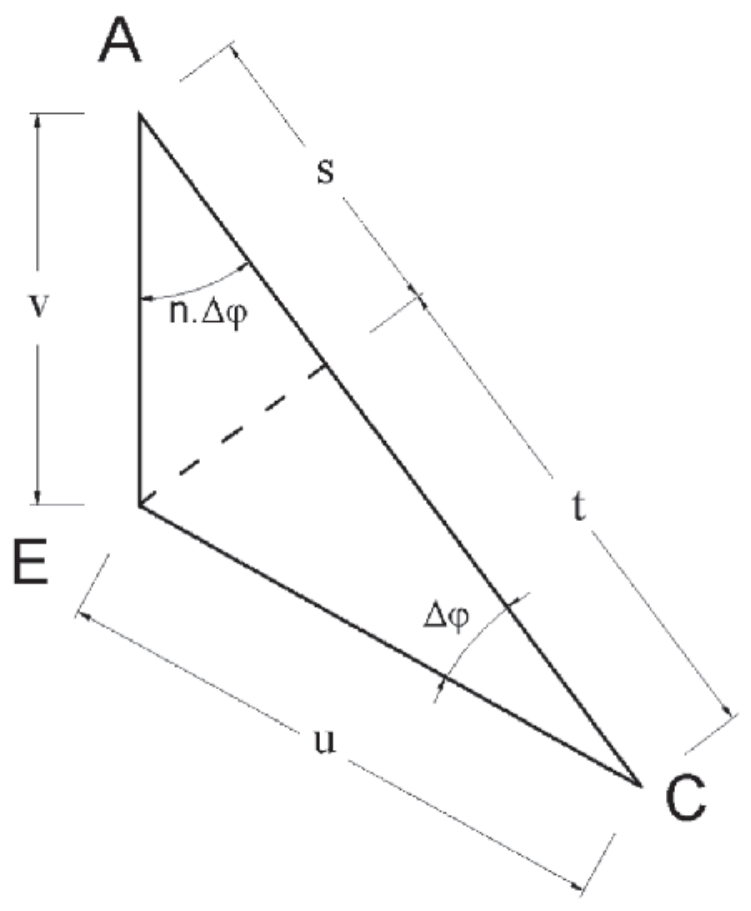

axis of the surface of a dome subjected to own weight with constant stress $\sigma=20 \mathrm{~N} / \mathrm{cm}^{2}$ and the specific weight of the material $\gamma=0,0236 \mathrm{~N} / \mathrm{cm}^{2}$, with $\varphi$ up to $70^{\circ}$.

The proposal automation, based on iterative process shown by [5], is made by taking up the triangle ACE in Figure 12, shown in Figure 13. Once $r_{\text {topo }}$ is calculated, one chooses a $\Delta \varphi$ for determining radii $r_{2}, r_{1}, r_{2, n}$, and so forth. The radius $r_{2, n}$ is given by:

$$
r_{2, n}=r_{1}-u
$$

where

$u=\sec (\Delta \varphi)\left\{[s+t] \div\left[\frac{\tan (\Delta \varphi)}{\tan (n \cdot \Delta \varphi)}+1\right]\right\}$

The value of $n$ refers to the iteration in which it is determined the value of $r_{2}$.

The geometry of the meridian can be obtained with no dependence on the thickness $h$, using only the equation (30). However, unlike other thin shells of revolution, as the cylinder or closed reservoirs, the use alone of this equation is not sufficient to establish a condition of constant stress across the dome.

To determine the variation of the thickness ong the dome height, an infinitesimal element of the mean shell surface with side $d s$ must be considered, as shown in Figure 14.
It is observed from Figure 14 that the presence of a load in the direction of the meridian requires a force to equilibrate it, thus it is imperative to have have an increase $d h$ on the lower side of the infinitesimal element.

The approximate equilibrium equation of the forces on the meridian of the dome can be obtained in Figure 14 and is given by:

$\sigma h d s+\gamma h d s^{2} \operatorname{sen} \varphi-\sigma(h+d h) d s=0$

Or by dividing the equation by $d s$ :

$\sigma d h=\gamma h d s \operatorname{sen} \varphi$

In Figure 14 it is seen that $d s \operatorname{sen} \varphi=d l$, where $d l$ is the variation in vertical height of the dome, starting from its top. Then :

$$
\frac{\mathrm{dh}}{\mathrm{h}}=\frac{\gamma}{\sigma} \mathrm{dl}
$$

Integrating (32):

$$
\ln h=\frac{\gamma}{\sigma} l+\mathbb{C}
$$

or

$$
h=\mathbb{C} e^{\gamma l / \sigma}=h_{0} e^{\gamma l / \sigma}
$$

$h_{0}$ being the thickness of the dome at the top, where $l=0$.

\section{Figure 14 - Meridional equilibrium of an infinitesimal element of the dome (5)}

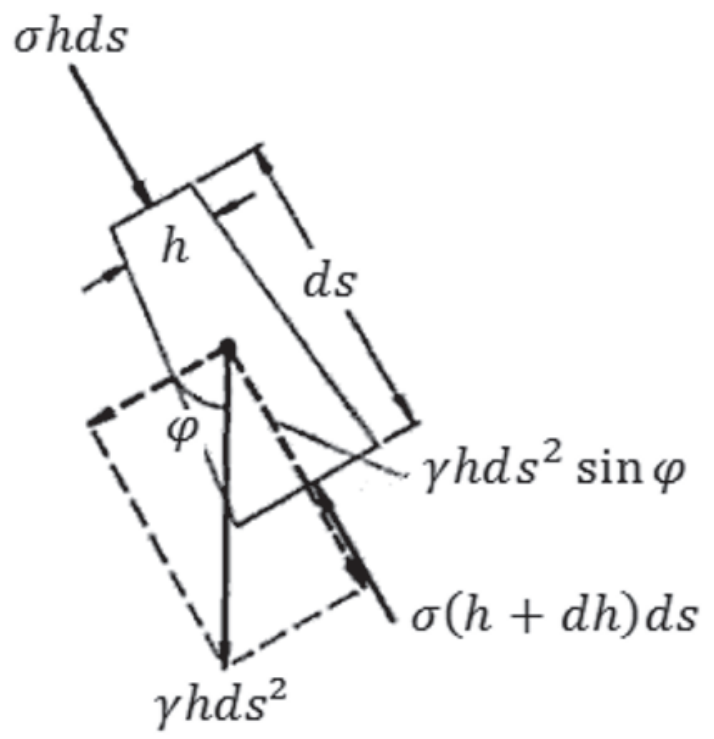


Figure 15 - Variation of the thickness

$h\left(h_{\text {topo }}<h_{\text {base }}\right)$ em uma cúpula com tensōes constantes

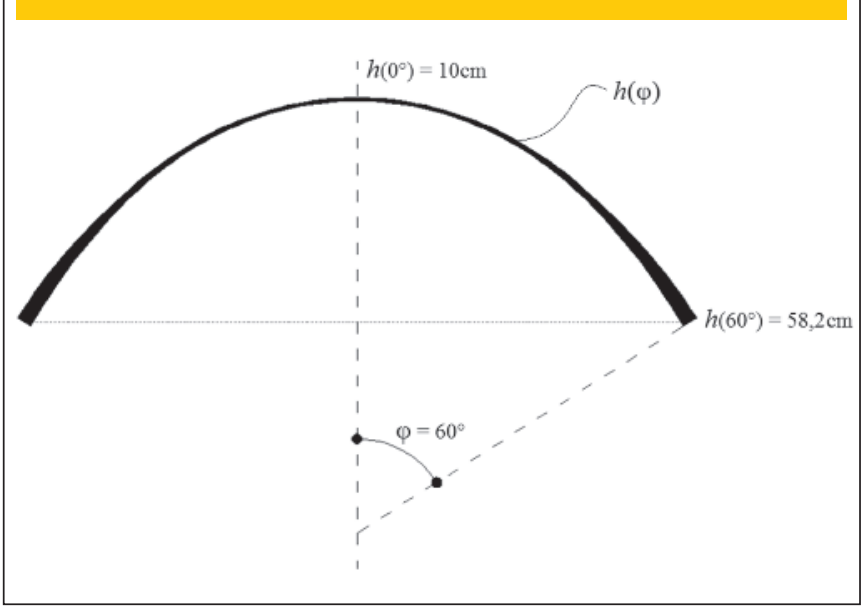

Figure 15 shows a dome subjected to its own weight with constant stress. From equations (27) and (33), it is observed that the thickness at the top of the dome is not dependent on any external factor, so $h_{0}$ may have any initial value, since it depends only on its own weight.

The automation of calculation $h$ can be performed using Figure 13 , wherein for each value of $\varphi, l$ can be obtained by:

$$
\mathrm{l}_{\mathrm{n}}=\mathrm{r}_{\text {topo }}+\sum_{\mathrm{n}=1}^{\mathrm{i}} \mathrm{v}_{\mathrm{n}}-\mathrm{r}_{2, \mathrm{n}} \cdot \cos (\mathrm{n} \cdot \Delta \varphi)
$$

where $n$ is the iteration number for the value of

$l$ for the cumulative $\Delta \varphi$.

\section{Results}

\subsection{Dome with constant stress}

To explain the differences between spherical domes with uniform thickness and domes with constant tensions subjected to own weight, an example for comparison is presented.

The dome with constant stress $\sigma=20 \mathrm{~N} / \mathrm{cm}^{2}$ (compression in both directions) has a thickness at the top $h_{0}=10 \mathrm{~cm}$, specific weight $\gamma=0,0236 \mathrm{~N} / \mathrm{cm}^{3}$, which results in a initial radius of curvature at the top $r_{1}=r_{2}=r_{\text {topo }}=1.695 \mathrm{~cm}$. The angle $\varphi$ ranges from $0^{\circ}$ up to $60^{\circ}$, with $\Delta \varphi$ equal to $0.1^{\circ}$.

The spherical dome has a constant thickness $h=10 \mathrm{~cm}$ and its radius of curvature is equal to the top radius of curvature of the dome with constant stresses $(r=1.695 \mathrm{~cm})$. The specific weight is $\gamma=0,0236 \mathrm{~N} / \mathrm{cm}^{3}$, which angle $\varphi$ also varies from $0^{\circ}$ up to $60^{\circ}$.

Figure 16 shows the stresses diagram developed in the spherical dome. Figure 17 and Table 1 show the variation of the thickness and radius of curvature $r_{1}$ and $r_{2}$ along the dome height with constant stresses.

The meridian and the thickness of the two domes (scale 2: 1 for the radius of curvature ) are shown in Figure 18.

It is noticed that, in the example, the spherical dome has higher compressive stresses along $\varphi$, and tensile stresses in the direction $\theta$. As the $\gamma / \sigma$ ratio is very small, even when considering a conservative stress, the dome radii of curvature with constant stress always increases as $\varphi$ increases, which means that domes subjected to their own weight are higher in relation to equivalent spherical domes with equal initial radius when considering the same . but smaller in height when considering the same $r_{0}$. This is repeated for virtually all materials used in construction. Because there are only compression stress, the use of materials not resistant to traction is possible, and the conditions necessary to support the dome are improved. Furthermore, the fact that there is only one solicitant stress value in the two axes, leads to an increased structural performance of the dome due to the better utilization of the

\section{Figure 16 - Tangential stressess \\ $\sigma_{\theta}$ and meridional stresses}

$\sigma_{\varphi}$ on the spherical dome, with constant thickness and radii of curvature

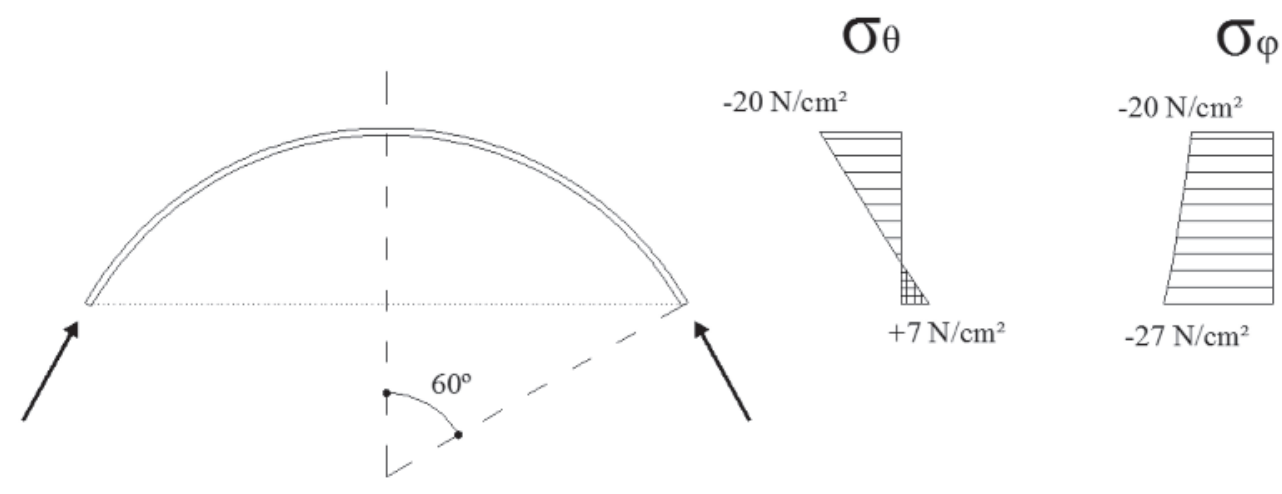




\section{Figure 17 - Thickness and radii of curvature of the dome with constant stress}

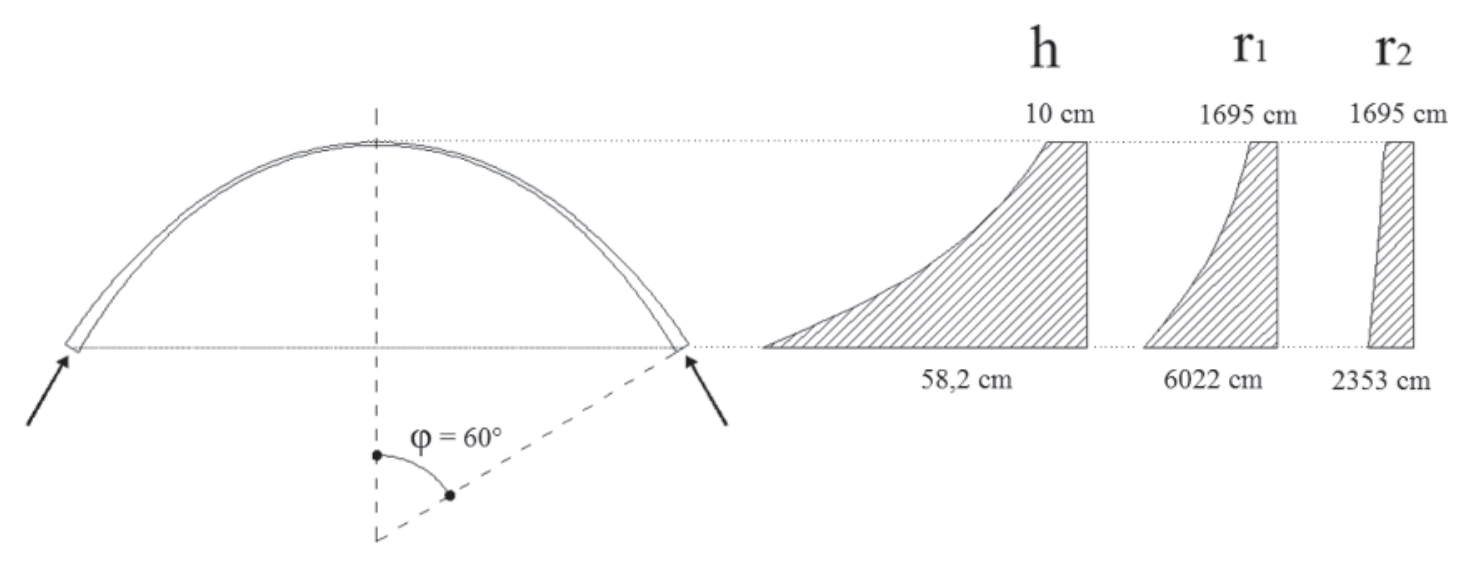

material.

The initial thickness of the dome with constant stress $h_{0}$ is multiplied by $e$ as $\varphi$ increases by a factor of $\gamma / \sigma$. It is noticed that the inverse relation $\gamma / \sigma$ is equal to half of $r_{\text {topo }}$. Thus, $h_{0}$ increases exponentially in function of $\varphi$ when $l$ is greater than $r_{\text {topo }} / 2$, as shown in Table 1 with $\varphi \geq 50^{\circ}$.

\subsection{Convergence process and limits of geometry}

The results obtained by the process are dependent on the input data initial stress $\sigma$, specific weight of material $\gamma$ and integration step $\Delta \varphi$. The higher the value $\Delta \varphi$, the lower the quality of the values obtained. Figure 18 shows the convergence of $r_{1}$ as $\Delta \varphi$ is reduced for the dome of the previous example with $\varphi=60^{\circ}$.

It can be seen that with $\Delta \varphi$ close to $0,1^{\circ}$, the radius of curvature of the results begin to converge. The same is seen in Figure 20 for the thickness $h$, which convergence is also true with $\Delta \varphi$ close to $0,1^{\circ}$. In other simulations, this same value of $\Delta \varphi$ seemed suitable for the convergence of the results.
In order to make the formulations of the membrane for domes valid, the conditions must be met:

$$
\mathrm{h} \leq 0,1 . \mathrm{r}_{0}
$$

as shown in Figure 2. Figure 21 shows the convergence of the maximum angle $\varphi$ as a function of $\Delta \varphi$, to meet the relation (35).

It is observed that around $\Delta \varphi=1^{\circ}$ there is already a convergence to the maximum value of $\varphi$ to meet the validity of the membrane model in the example shown. The maximum value of $\varphi$ is dependent on the initial stress and the specific weight of the material, therefore variable.

\section{Conclusions}

This paper presents an automatic process to define the geometry of axisymmetric domes subjected to their own weight by the

\section{Table 1 - Geometry of dome with constant stress in function of $\varphi$ with $\Delta \varphi=0,1^{\circ}$}

\begin{tabular}{|ccccc|}
$\begin{array}{c}\text { Angle } \\
\varphi\end{array}$ & $\begin{array}{c}\text { Height } \\
\text { I (cm) }\end{array}$ & $\begin{array}{c}\text { Thickness } \\
\mathrm{h}(\mathrm{cm})\end{array}$ & $\begin{array}{c}\text { Radius of curvalure } \\
\mathrm{r}_{1}(\mathrm{~cm})\end{array}$ & $\begin{array}{c}\text { Radius of curvature } \\
\mathrm{r}_{2}(\mathrm{~cm})\end{array}$ \\
\hline $0^{\circ}$ & 0 & 10,0 & 1695 & 1695 \\
$10^{\circ}$ & 21 & 10,3 & 1728 & 1704 \\
\hline $20^{\circ}$ & 107 & 11,6 & 1866 & 1745 \\
$30^{\circ}$ & 252 & 13,5 & 2123 & 1815 \\
$40^{\circ}$ & 485 & 17,7 & 2601 & 1925 \\
$50^{\circ}$ & 853 & 27,4 & 3566 & 2092 \\
$60^{\circ}$ & 1492 & 58,2 & 6022 & 2359 \\
$69^{\circ}$ & 2744 & 254,9 & 14932 & 2810 \\
\hline
\end{tabular}




\section{Figure 18 - Spherical dome and dome with constant stress}
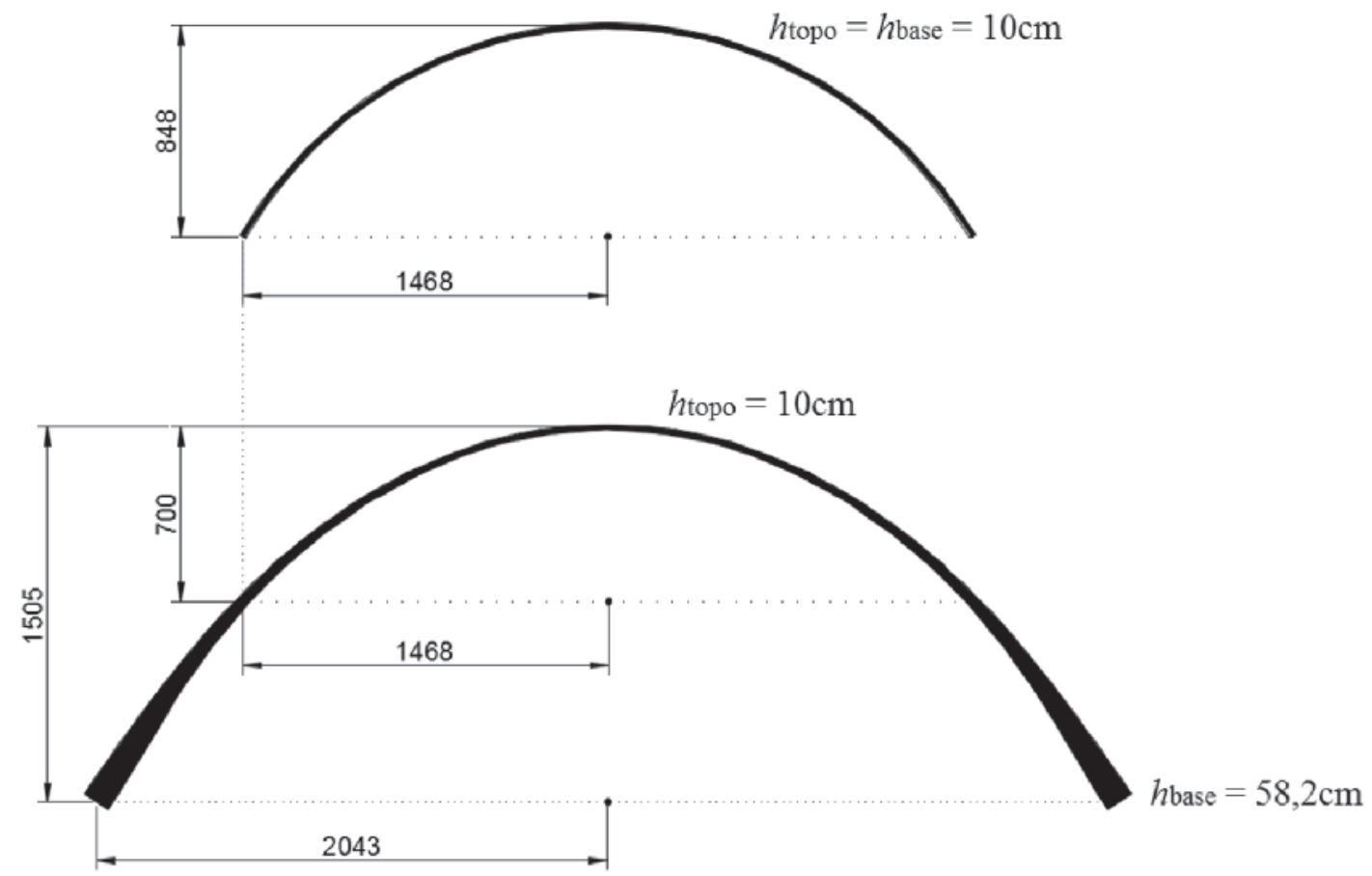

membrane theory with varying thickness and radii of curvature, in order to obtain constant meridional and tangential stresses. The results show that domes subjected to own weight generally have greater heights than the equivalent spherical ones with the same initial radius for the same $\varphi$, but have lower heights for the same $r_{0}$ due to the relationship $\gamma / \sigma$ being so small. Therefore, even when for a conservative initial stress, the radii of curvature of the dome with constant stress always increase as $\varphi$ increases.

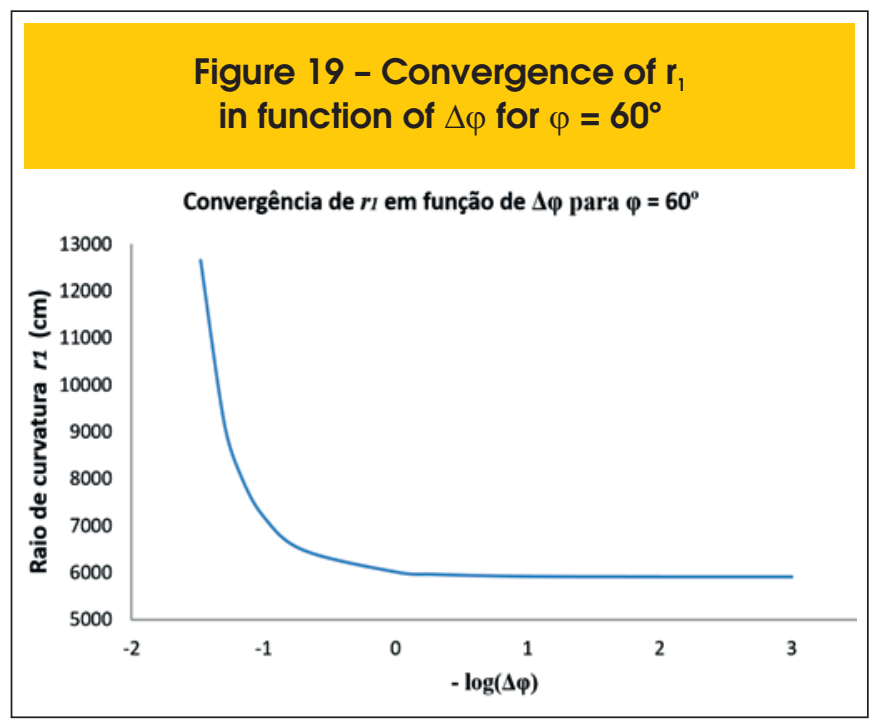

Regarding the presented process, it is clear that the accuracy of the results is a function of $\Delta \varphi$. For different configurations of $\gamma$ and $\sigma$, it was found that the convergence of results starts with values of $\Delta \varphi$ below $0,1^{\circ}$. For the validity of the membrane model, it is assured that the equation (35) is respected in order to keep the error of the variation of normal stress along the thickness of the dome small. The convergence in the example shown was around $\varphi=69^{\circ}$, though this value varies with the initial data used for the dome with constant stress.

The automatic process proposed to define the geometry of axi-

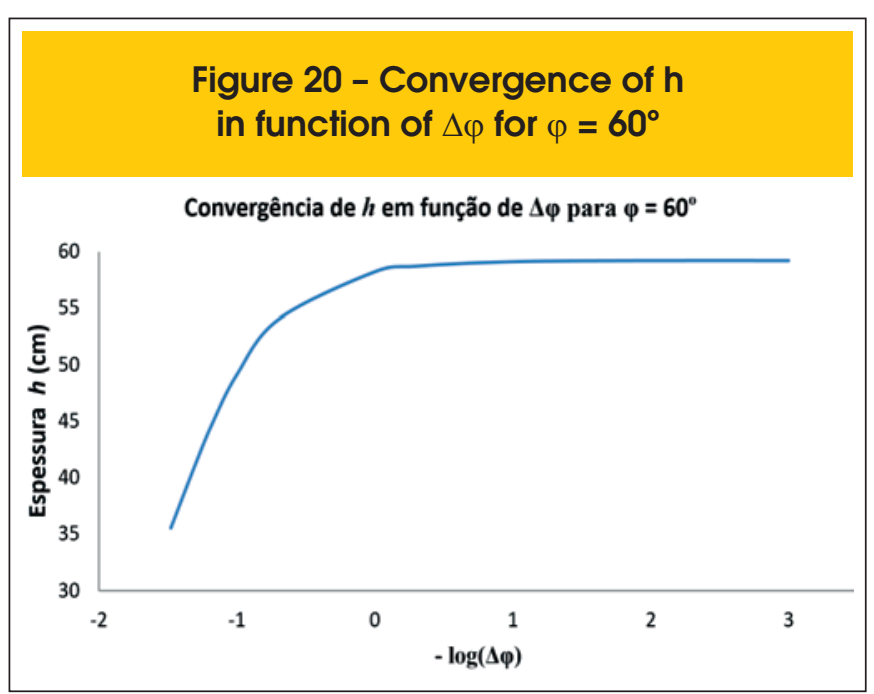


Figure 21 - Convergence of the limit value of $\varphi$ for the validity of the membrane model

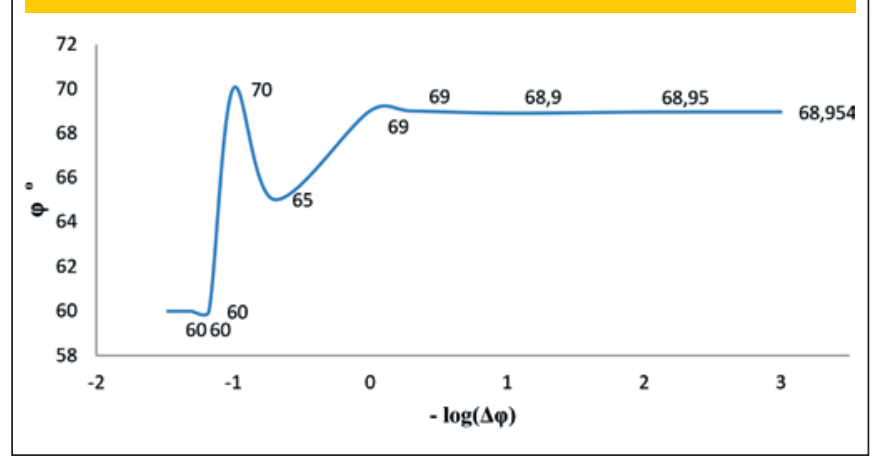

symmetric domes with constant stress subjected to own weight is simple to use and has a great advantage over the usual numeric methods. The process shown is also quite interesting for solving such structures as the analytical solutions to the problem are not easy to obtain. The tool is shown to be adequate, therefore, for the geometry defining of domes with constant stress for subsequent design.

\section{Referências bibliográficas}

[1] ABDESSALEM, J. FAKHREDDINE, D. SAID, A. MOHAMED, $\mathrm{H}$. Shape optimization for a hyperelastic axisymmetric structure. Journal of Engineering, Design and Technology, v.12, n.2, 2014; p.177-194.

[2] BLETZINGER, K.U. WÜCHNER, R. DAOUD, F CAMPRUBÍ, $\mathrm{N}$. Computational methods for form finding and optimization of shell and membranes. Computer Methods in Applied Mechanics and Engineering, v.194, n.30, 2005; p.3438-3452.

[3] CAMPUBRÍ, N. BISCHOFF, M. BLETZINGER, K.U. Shape optimization of shells and locking. Computers and Structures, n.82, 2004; p.2551-2561.

[4] ESPATH, L.F.R. LINN, R.V. AWRUCH, A.M. Shape optimization of shell structures based on NURBS description using automatic differentiation. Internatiotnal Journal for Numerical Methods in Engineering, v.88, n.7, 2011; p.613-636.

[5] HARTOG, J. P. D. Advanced Strength of Materials. McGrawHill Book Company, New York, 1952, 401 p.

[6] ITALY'S best, The Pantheon. Disponível em <http://www.italysbestrome.com/the-pantheon/> Acesso em 27 de julho de 2015.

[7] KIENDL, J. SCHMIDT, R. WÜCHNER, R., BLETZINGER, K.U. Isogeometric shape optimization of shells using semianalytical sensitivity analysis and sensitivity weighting. Computer Methods in Applied Mechanics and Engineering, v.274, 2014; p. 148-167.

[8] LINN, R. V. Otimização de forma de cascas axissimétricas utilizando diferenciação automática. Monografia de graduação. UFRG. Porto Alegre, 2010, 92 p.

[9] MARK, R. HUTCHINSON, P. On the structure of the Roman Pantheon. College Art Association. The Art Bulletin. Vol. 68, No. 1, p. 24-34. Março de 1986.

[10] POPOV, E. P. Introdução à Mecânica dos Sólidos. Editora Edgard Blücher Ltda. São Paulo, 1978, 534 p.
[11] POPOV, E. P. Engineering Mechanics of Solids. PrenticeHall. New Jersey, 1999, 891 p.

[12] Rasch, J. The Dome of the Roman Architecture. Development, Design, Construction. Architectura 15; p. 117-139. 1985.

[13] TIMOSHENKO, S. P. GERE, J. M. Mecânica dos sólidos, v.1. LTC. Rio de Janeiro, 1983, 258 p.

[14] TIMOSHENKO, S. P. GOODIER, J. N. Theory of Elasticity. McGraw-Hill Book Company, Nova Yorque, 1951.

[15] TIMOSHENKO, S. P. WOINOWSKY-KRIEGER, S. Theory of Plates and Shells, McGraw-Hill Kogagusha LTD., International Student Edition, 1959, 591 p. 